\title{
Awareness, behavior and attitudes concerning sun exposure among beachgoers in the northern coast of Peru
}

\author{
Carlos J Toro-Huamanchumo ${ }^{\text {Corresp., }}{ }^{1}$ ， Sara J Burgos-Muñoz ${ }^{2}$ ， Luz M Vargas-Tineo ${ }^{2}$, Jhosuny Perez-Fernandez ${ }^{2}$

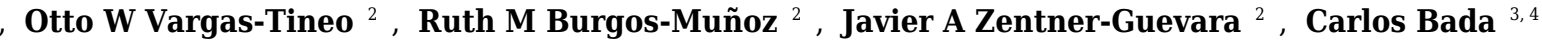 \\ ${ }^{1}$ Centro de Investigación en Epidemiología Clínica y Medicina Basada en Evidencias, Universidad de San Martín de Porres, Lima, Peru \\ 2 School of Medicine, Universidad de San Martín de Porres, Chiclayo, Peru \\ 3 School of Medicine, Universidad de San Martín de Porres, Lima, Peru \\ 4 Clínica San Judas Tadeo, Lima, Peru \\ Corresponding Author: Carlos J Toro-Huamanchumo \\ Email address: carlos_toro@usmp.pe
}

Background: Skin cancer incidence has increased over the last years, becoming a major public health problem.

Objective: To describe the awareness, behavior and attitudes concerning sun exposure among beachgoers in the northern coast of Peru.

Methods: We conducted a cross-sectional study in the Pimentel beach, Peru. The "Beach Questionnaire" was used and we surveyed all the beachgoers from 8 a.m. to 4 p.m. and from March 5 to March 19. For the statistical analysis, sun exposure habits, sunburns history, knowledge, attitudes and practices were crossed with sex using the chi2 test.

Results: We surveyed 410 beachgoers, the most frequent phototype was type III (40.5\%). Only the $13.66 \%$ of the respondents correctly answered the seven knowledge questions related to sun exposure and skin cancer. Men were more frequently agreed that "when they are tanned their clothes looks nicer" $(p=0.048)$. Likewise, regarding the questions "Sunbathing is relaxing" and "Sunbathing improves my mood", men agreed or totally agreed with more frequency than women $(63.64 \%$ vs. $46.15 \%, p<0.001$; and $61.36 \%$ vs $49.15 \%, p=0.014$, respectively). Regarding sun protection practices, women more frequently used sunshade $(p=0.001)$ and sunscreen $(S P F \geq 15)(p<0.001)$ when compared to the male group.

Conclusion: Sun exposure is a potentially preventable risk factor for skin cancer. Thus, awareness of the risks of UVR overexposure and adequate sun-protective behaviors and attitudes are essential. Our results, however, are not as favorable as expected. Public Health efforts should encourage sun-safety precautions and intervention campaigns should be carried out in recreational settings, such as the beaches. 
1 Awareness, behavior and attitudes concerning sun exposure among beachgoers in the 2 northern coast of Peru

3 Carlos J. Toro-Huamanchumo ${ }^{1}$, Sara J. Burgos-Muñoz ${ }^{2}$, Luz M. Vargas-Tineo², Jhosuny Perez-

4 Fernandez ${ }^{2}$, Otto W. Vargas-Tineo ${ }^{2}$, Ruth M. Burgos-Muñoz ${ }^{2}$, Javier A. Zentner-Guevara ${ }^{2}$, Carlos

$5 \operatorname{Bada}^{3,4}$

6

$7 \quad{ }^{1}$ Centro de Investigación en Epidemiología Clínica y Medicina Basada en Evidencias, Universidad

8 de San Martín de Porres, Lima, Peru

$9{ }^{2}$ School of Medicine, Universidad de San Martín de Porres, Chiclayo, Peru

$10{ }^{3}$ School of Medicine, Universidad de San Martín de Porres, Lima, Peru

$11{ }^{4}$ Clínica San Judas Tadeo, Lima, Peru

14 Short title: Sun exposure among Peruvian beachgoers

16 Corresponding author:

17 Carlos J. Toro-Huamanchumo

18 Centro de Investigación en Epidemiologia Clínica y Medicina Basada en Evidencias, Universidad 19 de San Martin de Porres, Lima, Peru

20 Avenida Alameda del Corregidor 1531, La Molina. Lima, Peru

21 Phone: +51944942888

22 E-mail: toro2993@hotmail.com 


\section{ABSTRACT}

24 Background: Skin cancer incidence has increased over the last years, becoming a major public 25 health problem.

26 Objective: To describe the awareness, behavior and attitudes concerning sun exposure among 27 beachgoers in the northern coast of Peru.

28 Methods: We conducted a cross-sectional study in the Pimentel beach, Peru. The "Beach 29 Questionnaire" was used and we surveyed all the beachgoers from 8 a.m. to 4 p.m. and from March 305 to March 19. For the statistical analysis, sun exposure habits, sunburns history, knowledge, 31 attitudes and practices were crossed with sex using the chi2 test.

32 Results: We surveyed 410 beachgoers, the most frequent phototype was type III (40.5\%). Only 33 the $13.66 \%$ of the respondents correctly answered the seven knowledge questions related to sun 34 exposure and skin cancer. Men were more frequently agreed that "when they are tanned their 35 clothes looks nicer" ( $\mathrm{p}=0.048)$. Likewise, regarding the questions "Sunbathing is relaxing" and 36 "Sunbathing improves my mood", men agreed or totally agreed with more frequency than women 37 (63.64\% vs. $46.15 \%, \mathrm{p}<0.001$; and $61.36 \%$ vs $49.15 \%, \mathrm{p}=0.014$, respectively). Regarding sun 38 protection practices, women more frequently used sunshade $(\mathrm{p}=0.001)$ and sunscreen $(\mathrm{SPF} \geq 15)$ $39(\mathrm{p}<0.001)$ when compared to the male group.

40 Conclusion: Sun exposure is a potentially preventable risk factor for skin cancer. Thus, awareness 41 of the risks of UVR overexposure and adequate sun-protective behaviors and attitudes are 42 essential. Our results, however, are not as favorable as expected. Public Health efforts should 43 encourage sun-safety precautions and intervention campaigns should be carried out in recreational 44 settings, such as the beaches. 


\section{BACKGROUND}

47 Skin cancer incidence has increased over the last years, becoming a major public health problem

48 with a serious economic burden to the healthcare system of many countries (1-3). According to 49 GLOBOCAN estimates, about 232.000 cases of melanoma and 55.000 deaths from this cause 50 occurred worldwide in 2012 (4).

51

52 In recent years, global incidence rates of skin cancer have increased and there are some published 53 reports that evidence this situation. For example, melanoma raw incidence rates per 100000 US 54 population has climbed from 22.2 to 23.6 (2009-2016 period). Similarly, raw mortality rates per 55100000 population has increased from 2.8 to 3.1 (5). In Europe, melanoma trends has also 56 increased in recent years, with the highest incidence rates in the UK, Ireland and the Netherlands 57 (6). Unfortunately, available data for Latin America is very limited (7). In Peru, there has been 58 reported a growing trend of skin cancer, becoming the fourth most frequent type of cancer in the 59 country (8).

60

61 Sun exposure is considered a potentially preventable risk factor for skin cancer (9) and an adequate

62 knowledge and good practices play an important role in the prevention of the disease. In fact, some 63 studies have been carried out in order to assess these variables in patients, workers and students 64 (10-15). However, only a few have focused on beachgoers, who are an important population at 65 risk (16-18), and two of these studies only focused on behaviors and did not address knowledge 66 or attitudes. In addition, the countries where these studies were conducted have a UV index lower 67 than that reported in Peru (19). 
69 In Peru, high temperature peaks have been reported over the last years, especially in 2017 (20). In

70 addition, Peru has been cataloged by the National Meteorology and Hydrology Service

71 (SENAMHI) as one of the countries with the highest solar radiation, reaching an index of

72 ultraviolet radiation (UV index) of 19 on a scale of 0 to 20 (20). The northern coast of Peru has a

73 semi-warm and tropical-dry climate where rainfall is barely present $(21,22)$. In summer, this region

74 becomes even warmer, surpassing $30^{\circ} \mathrm{C}(20,21)$.

75

76 For the above mentioned, the objective of the present study was to describe the awareness,

77 behavior and attitudes concerning sun exposure among beachgoers in the northern coast of Peru.

78

79

80

81

82

83

84

85

86

87

88

89

90

91 


\section{METHODS}

95 Study design

96 We conducted a cross-sectional study in the Pimentel beach, Peru.

97

Setting and Participants

99 Pimentel is one of the main beaches in the northern Peru and belongs to Lambayeque, which is 100 considered a semi-warm and tropical-dry region, with temperatures that exceed $30^{\circ} \mathrm{C}$ during 101 summer (20,21) (Figure 1).

102

103 We surveyed all the beachgoers from 8 a.m. to 4 p.m. and from March 5 to March 19 (Peruvian 104 summer, 2018) (20). No sample was calculated. We surveyed all Spanish-speaking adults aged 18 105 to 59 who were in the study place within the specified time range.

106

107

Variables and Data collection

108 We applied the "Beach Questionnaire", validated by de Troya M et al (2009) in a sample of Spanish 109 beachgoers (23). This instrument aims to evaluate subjects' behavior, attitudes and knowledge 110 regarding sun exposure, and has been used in previous studies with similar populations $(24,25)$. It 111 has also been shown to be valid, reliable (Cronbach $\alpha>0.7$ ) and with good sensitivity to change $112(23,26)$. 
114 The questionnaire included all our study variables and had the following sections: 1)

115 Sociodemographic and academic data: sex, age, marital status, country of birth and educational

116 level; 2) Color of non-sun-exposed skin: very fair, fair olive and dark; 3) Phototype: according to

117 the Fitzpatrick model: I-IV, according to the erythema and tanning response after the first 60-

118 minute sun exposure in summer $(25)$; 4) Sun exposure habits on the beach in the last two summers:

119 number of days spent at the beach each last two summers, number of hours per day and number of

120 hours at midday (defined as between 12.00-16.00); 5) Sunburns history in the last summer

121 (sunburn was defined as painful reddening of the skin) (25); 6) Participants' general knowledge

122 about sun exposure with dichotomous response (true or false); 7) Attitudes related with sun

123 exposure and sun protection, on a Likert-like scale of five categories (from "totally disagree" to

124 "totally agree") and 8) Sun protection practices.

125

126 Statistical analysis

127 Collected data was entered into Microsoft Excel ${ }^{\circledR}$ with a double entry method to avoid errors 128 during the process. After quality control, the database was exported to Stata v13.0 (StataCorp LP, 129 College Station, TX, USA).

130

131 We used relative and absolute frequencies to describe categorical variables and medians with 132 interquartile ranges (after checking the absence of normality with Shapiro Wilk) for numerical 133 variables. For bivariate analysis, we compared the categorical variables according to sex using the 134 chi2 test. We considered a P-value $<0.05$ as statistically significant. 


\section{Ethics}

137 This study was approved by the Institutional Review Board of the Hospital Nacional Docente 138 Madre-Niño San Bartolome (RCEI-40), Lima, Peru. The participation was voluntary, and 139 participants provided their informed oral consent, prior filling the survey. The anonymity of the 140 participants and

data confidentiality

were

ensured. 


\section{RESULTS}

\section{Baseline characteristics of the study population}

143 We surveyed a total of 410 beachgoers. The most frequent skin colors were olive (46.6\%) and pale 144 (35.4\%). The most frequent Fitzpatrick phototype was type III (40.5\%). Detailed 145 sociodemographic and academic data are shown in table 1.

147 Sun-exposure habits and sunburns history

148 Men went to the beach more frequently in the last two summers $(20.46 \%$ went more than 15 days 149 vs $12.82 \%$ of women, $p=0.028$ ). Likewise, $62.2 \%$ of the participants reported having suffered at 150 least one sunburn last summer (Table 2).

151

\section{Knowledge about sun exposure}

153 Only the $13.66 \%$ of respondents $(n=56)$ correctly answered the seven questions related to sun 154 exposure and skin cancer (Table 3). Individual analysis showed that the following questions had the lower percentage of correct answers: "Sun protection creams prevent aging of the skin produced by solar radiation" (60.0\%) and "If I use total sun block I can sunbathe without any risk" (58.29\%). Likewise, according to sex, significant differences were found in the response to "Once my skin is tanned, I don't need to use sun protection cream" (76.14\% of men answered correctly, versus $88.46 \%$ of women, $\mathrm{p}=0.001)$.

160

161

\section{Attitudes related with sun exposure}

162 More than three quarters of the respondents agreed or totally agreed that it is necessary to use

163 sunscreen creams to avoid problems in the future $(90.49 \%)$ and that its use is worthwhile despite 
164 not getting a $\tan (77.80 \%)$ (Table 4$)$. Men were more frequently agreed that when they are tanned 165 their clothes looks nicer $(\mathrm{p}=0.048)$. Likewise, regarding the question "Sunbathing is relaxing", 166 men agreed or totally agreed with more frequency than women $(63.64 \%$ vs. $46.15 \%, p<0.001)$. 167 The same thing happened with the item "Sunbathing improves my mood" $(61.36 \%$ of men vs $16849.15 \%$ of women, $\mathrm{p}=0.014)$.

169

170 Sun protection practices

171 The $63.9 \%$ of the respondents indicated that they usually or always use sunscreen when they go

172 to the beach (Table 5). However, the compliance percentage was lower for the rest of the

173 practices. Analysis by sex showed that women more frequently used sunshade $(\mathrm{p}=0.001)$ and 174 sunscreen $(\mathrm{SPF} \geq 15)(\mathrm{p}<0.001)$. 


\section{DISCUSSION}

\section{Sun-exposure habits and sunburns history}

177 In our study, we found that men went with more frequency to the beach than women, which may

178 be related to recreational activities that are often performed at the place of study (e.g. surfing and 179 soccer). This finding differs from that found by Fernández T et al (2014). In their study, women 180 went to the beach more frequently (75.5\% compared to $66.4 \%$ of men) (15). However, this may 181 be because its population was comprised only of adolescents, which may be related to another of 182 their findings, which was a higher likelihood for sunbathing and tanning by the female group. 183

We found that more than $60 \%$ had suffered at least one sunburn in the last summer, a percentage 185 higher than those reported in studies conducted in the US $(27,28)$ and Europe $(25,29,30)$. This may 186 be due to the lack of education in the local population, which negatively affects their practices and habits regarding sun exposure. This finding is a call for the implementation of intervention and education strategies, since it has been demonstrated that a personal sunburns history is strongly associated with skin cancer $(1,2,31,32)$.

190

\section{Participants' general knowledge about sun exposure}

192 Less than $15 \%$ of the respondents correctly answered the seven questions about sun exposure. This 193 lack of knowledge could be a possible explanation for the growing trend of skin cancer in the

194 Peruvian population (8). Studies conducted in adolescents and adults beachgoers in Spain have 195 reported better levels of knowledge $(15,16)$, which could be a reflection of the positive impact of the interventions and campaigns that have been carried out in that country $(24,26,33)$. 
198 Some studies suggest that a good level of knowledge about sun exposure may not always go hand 199 in hand with adequate attitudes or practices (34-36). However, a systematic review showed that 200 some sun protection behaviors were positively associated with a good level of knowledge about 201 skin cancer (37). Also, a study conducted by de Troya M et al (2018) reported an important role 202 of knowledge about sun exposure in the prevention of sunburns (25).

203

204 Attitudes related with sun exposure

205 Most of the participants presented good attitudes regarding the use of sunscreen. These results are 206 more favorable to those found by Mousavi F et al (2011) (35) and Fernandez T et al (2017) (14). 207 A possible explanation may be that during the last summer, high temperature peaks were reported 208 in comparison to previous years, as well as heavy rains on the northern coast of Peru (20). To face 209 the problem, intervention, reconstruction and prevention activities were carried out, including 210 information campaigns which were disseminated by local and national media.

211

212 On the other hand, men presented inappropriate attitudes more frequently, which differs from the 213 results reported in two studies conducted in Spain $(14,15)$. A possible explanation may lie in the 214 continuing influence of social media on current stereotypes and the perception of beauty and body 215 image concerns $(38,39)$. In this sense, since tanning has usually been related to concepts of beauty, 216 our result could be understood a little more by the fact that nowadays men are increasingly 217 adopting some attitudes that were previously prioritized by women, such as sunbathing and tanning $218(14,29)$.

219

220 Sun protection practices 
221 More than half of the participants reported a frequent sunscreen use (usually or always). This result 222 is similar to that found by Devos et al (2012) in a sample of beachgoers from the northern coast of 223 Belgium (40), and better than those reported in other studies conducted in Europe $(15,18)$ and Asia $224(35,36)$. However, the percentages of compliance for the other practices were less than $50 \%$. Since 225 current literature mentions that sunscreen use alone is not enough to control the skin exposure to 226 UVR (41-43), beachgoers should adopt other measures, such as avoiding midday, wearing hat/cap 227 and long-sleeved clothes, seeking for shade and skin self-examination $(9,43-45)$.

228

229

230

231

232

233

234

235

236

237

238

239

240

241

242 243

Women had more and better sun protection practices, mainly related to the use of sunscreen and sunshade. Previous research have also reported better sun exposure behaviors and practices in this population $(18,36,40,46)$. This may be linked to the attitudes that, according to our study, were also better in women. In addition, this could explain why sunburns are more frequent in men, according to some studies $(25,47,48)$.

\section{Relevance and implications}

Skin cancer has become a major public health problem (1-3). In recent years, its global incidence rates have increased (5-7), and Peru is not the exception (8). Thus, awareness of the risks of sun exposure and adequate sun-protective behaviors and attitudes are needed. Our results, however, are not as favorable as expected.

Evidence suggest that Public Health efforts should encourage sun-safety precautions to avoid UVR overexposure $(29,49)$. In addition, beach seems to be an ideal setting for promoting adequate sunprotective behaviors (16). In this sense, prevention, detection and intervention campaigns related 
244 to sun protection and skin cancer should be carried out, as they have shown satisfactory results in 245 other studies $(17,24,33,50)$.

246

247 Limitations

248 Some limitations must be highlighted. First, we used self-report questions; despite using a 249 validated instrument to measure our variables, social desirability bias might arise. Second, we did 250 not address some variables that could potentially influence the results of our study, such as current 251 or previous illnesses and family history of skin cancer. Finally, the extrapolation of our results is

252 limited to the Pimentel beachgoers. However, given that it is the busiest beach in Lambayeque, it 253 gives us a good approximation to the possible reality in the region.

254

255 Conclusion

256 Only one or two out of ten respondents correctly answered all the questions related to sun exposure 257 knowledge. Negative attitudes were more frequent in men, and women presented better practices. 258 Future research should study other variables that are also related to sun protection. Thus, 259 interventions could be more targeted and with even more promising results. Finally, we 260 recommend that future studies develop and evaluate the impact of sun-protective interventions, as 261 previous research have shown their potential to promote sun protection in recreational settings $262(51-53)$.

263

264 ACKNOWLEDGMENT

265 None 


\section{AUTHORS' CONTRIBUTIONS}

268 CJT-H and SJB-M conceived the idea of the manuscript. SJB-M, LMV-T, JP-F, OWV-T, RMB-

$269 \mathrm{M}$ and JAZ-G collected the data. CJT-H and CB performed the statistical analyses and wrote the 270 first draft. All authors read and approved the final manuscript. 


\section{REFERENCES}

272 1. Erdmann F, Lortet-Tieulent J, Schüz J, Zeeb H, Greinert R, Breitbart EW, Bray F. 273 International trends in the incidence of malignant melanoma 1953-2008--are recent generations 274 at higher or lower risk? Int J Cancer. 2013;132(2):385-400.

275 2. Garbe C, Leiter U. Melanoma epidemiology and trends. Clin Dermatol. 2009;27(1):3-9.

276 3. Guy GP, Machlin SR, Ekwueme DU, Yabroff KR. Prevalence and costs of skin cancer 277 treatment in the U.S., 2002-2006 and 2007-2011. Am J Prev Med. 2015;48(2):183-7.

278 4. Ferlay J, Soerjomataram I, Dikshit R, Eser S, Mathers C, Rebelo M, Parkin DM, Forman 279 D, Bray F. Cancer incidence and mortality worldwide: sources, methods and major patterns in 280 GLOBOCAN 2012. Int J Cancer. 2015;136(5):E359-386.

281 5. Glazer AM, Winkelmann RR, Farberg AS, Rigel DS. Analysis of Trends in US Melanoma 282 Incidence and Mortality. JAMA Dermatol. 2017;153(2):225-6.

283 6. Arnold M, Holterhues C, Hollestein LM, Coebergh JWW, Nijsten T, Pukkala E, Holleczek 284 B, Tryggvadóttir L, Comber H, Bento MJ, Diba ChS, Micallef R, Primic-Žakelj M, Izarzugaza MI, 285 Perucha J, Marcos-Gragera R, Galceran J, Ardanaz E, Schaffar R, Pring A, de Vries E. Trends 286 in incidence and predictions of cutaneous melanoma across Europe up to 2015. J Eur Acad 287 Dermatol Venereol. 2014;28(9):1170-8.

288 7. Schmerling RA, Loria D, Cinat G, Ramos WE, Cardona AF, Sánchez JL, Martinez-Said $289 \mathrm{H}$, Buzaid AC. Cutaneous melanoma in Latin America: the need for more data. Rev Panam Salud 290 Publica. 2011;30(5):431-8.

291 8. Sordo C, Gutiérrez C. Cáncer de piel y radiación solar: experiencia peruana en la 292 prevención y detección temprana del cáncer de piel y melanoma. Rev Peru Med Exp Salud 293 Pública. 2013;30:113-7.

294 9. Molho-Pessach V, Lotem M. Ultraviolet radiation and cutaneous carcinogenesis. Curr 295 Probl Dermatol. 2007;35:14-27. 
296 10. Thomas-Gavelan E, Sáenz-Anduaga E, Ramos W, Sánchez-Saldaña L, Sialer M del C. 297 Knowledge, attitudes and practices about sun exposure and photoprotection in outpatients 298 attending dermatology clinics at four hospitals in Lima, Peru. An Bras Dermatol. 2011;86(6):11222998.

300 11. Lucena EE de S, Costa DCB, da Silveira EJD, Lima KC. Occupation and factors 301 associated with exposure to the sun among beach workers. Cienc Saude Coletiva. $302 \quad 2014 ; 19(4): 1171-8$.

303 12. Hault K, Rönsch H, Beissert S, Knuschke P, Bauer A. Knowledge of outdoor workers on 304 the effects of natural UV radiation and methods of protection against exposure. J Eur Acad 305 Dermatol Venereol. 2016;30 Suppl 3:34-7.

306 13. Gao Q, Liu G, Liu Y. Knowledge, attitude and practice regarding solar ultraviolet exposure 307 among medical university students in Northeast China. J Photochem Photobiol B. 2014;140:14308 9.

14. Fernández-Morano T, Rivas-Ruiz F, de Troya-Martín M, Blázquez-Sánchez N, Ruiz MP, 310 Buendía-Eisman A. Adolescents' Attitudes to Sun Exposure and Sun Protection. J Cancer Educ. $3112017 ; 32(3): 596-603$.

312 15. Fernández-Morano T, De Troya-Martín M, Rivas-Ruiz F, Blázquez-Sánchez N, Del Boz313 González J, Fernández-Peñas P, Buendía-Eisman A. Behaviour, attitudes and awareness 314 concerning sun exposure in adolescents on the Costa del Sol. Eur J Dermatol. 2014;24(1):85-93. 315 16. Cercato MC, Ramazzotti V, Sperduti I, Asensio-Pascual A, Ribes I, Guillén C, Nagore E. 316 Sun protection among Spanish beachgoers: knowledge, attitude and behaviour. J Cancer Educ. $3172015 ; 30(1): 4-11$.

318 17. Pagoto S, McChargue D, Fuqua RW. Effects of a multicomponent intervention on 319 motivation and sun protection behaviors among midwestern beachgoers. Health Psychol. $320 \quad 2003 ; 22(4): 429-33$. 
321 18. Weinstock MA, Rossi JS, Redding CA, Maddock JE, Cottrill SD. Sun protection behaviors 322 and stages of change for the primary prevention of skin cancers among beachgoers in 323 southeastern New England. Ann Behav Med Publ Soc Behav Med. 2000;22(4):286-93.

324 19. Newman PA, McKenzie R. UV impacts avoided by the Montreal Protocol. Photochem 325 Photobiol Sci. 2011;10(7):1152-60.

326 20. Servicio Nacional de Meteorología e Hidrología. Perú: SENAMHI; 2017.

327 21. Oficina Nacional de Gobierno Electrónico e Informática. Sistema Nacional de Información 328 Geográfica Sayhuite. Perú; 2017.

329 22. Feddema JJ. A Revised Thornthwaite-Type Global Climate Classification. Phys Geogr. $330 \quad 2005 ; 26(6): 442-66$.

331 23. de Troya-Martín M, Blázquez-Sánchez N, Rivas-Ruiz F, Fernández-Canedo I, Rupérez332 Sandoval A, Pons-Palliser J, Perea-Milla E. Validación de un cuestionario en español sobre 333 comportamientos, actitudes y conocimientos relacionados con la exposición solar: «Cuestionario 334 a pie de playa». Actas Dermo-Sifiliográficas. 2009;100(7):586-95.

335 24. de Troya-Martín M, Delgado-Sánchez N, Blázquez-Sánchez N, Ortega-Tudela G, Toribio336 Montero JC, Jabalera-Mesa ML, Ríos-Almellones I, Rivas-Ruiz F. Skin cancer prevention 337 campaign aimed at beachgoers on the Costa del Sol (southern Spain). Int J Dermatol. 338 2014;53(11):e526-530.

339 25. de Troya-Martín M, de Gálvez-Aranda MV, Rivas-Ruiz F, Blázquez-Sánchez N, 340 Fernández-Morano MT, Padilla-España L, Herrera-Ceballos E. Prevalence and predictors of 341 sunburn among beachgoers. Photodermatol Photoimmunol Photomed. 2018;34(2):122-9.

342 26. Fernández-Morano T, de Troya-Martín M, Rivas-Ruiz F, Blázquez-Sánchez N, Buendía-

343 Eisman A. Sensitivity to change of the Beach Questionnaire to behaviour, attitudes and 344 knowledge related to sun exposure: quasi-experimental before-after study. BMC Public Health. $345 \quad 2015 ; 15: 60$. 
346 27. Buller DB, Cokkinides V, Hall HI, Hartman AM, Saraiya M, Miller E, Paddock L, Glanz K. 347 Prevalence of sunburn, sun protection, and indoor tanning behaviors among Americans: review 348 from national surveys and case studies of 3 states. J Am Acad Dermatol. 2011;65(5 Suppl 349 1):S114-123.

350 28. Holman DM, Berkowitz Z, Guy GP, Hartman AM, Perna FM. The association between 351 demographic and behavioral characteristics and sunburn among U.S. adults - National Health 352 Interview Survey, 2010. Prev Med. 2014;63:6-12.

353 29. Haluza D, Simic S, Höltge J, Cervinka R, Moshammer H. Gender aspects of recreational 354 sun-protective behavior: results of a representative, population-based survey among Austrian 355 residents. Photodermatol Photoimmunol Photomed. 2016;32(1):11-21.

356 30. Kritsotakis G, Psarrou M, Vassilaki M, Androulaki Z, Philalithis AE. Gender differences in 357 the prevalence and clustering of multiple health risk behaviours in young adults. J Adv Nurs. $358 \quad 2016 ; 72(9): 2098-113$.

359 31. Sánchez G, Nova J, de la Hoz F. Risk Factors for Basal Cell Carcinoma: A Study From 360 the National Dermatology Center of Colombia. Actas Dermo-Sifiliográficas. 2012;103(4):294-300.

361 32. Wu S, Cho E, Li W-Q, Weinstock MA, Han J, Qureshi AA. History of Severe Sunburn and 362 Risk of Skin Cancer Among Women and Men in 2 Prospective Cohort Studies. Am J Epidemiol. 363 2016;183(9):824-33.

364 33. del Boz J, Fernández-Morano T, Padilla-España L, Aguilar-Bernier M, Rivas-Ruiz F, de 365 Troya-Martín M. Campaña de prevención y detección de cáncer cutáneo en campos de golf de 366 la Costa del Sol. Actas Dermo-Sifiliográficas. 2015;106(1):51-60.

367 34. Haluza D, Simic S, Moshammer H. Sun Exposure Prevalence and Associated Skin Health 368 Habits: Results from the Austrian Population-Based UVSkinRisk Survey. Int J Environ Res Public 369 Health. 2016;13(1). 
370 35. Mousavi F, Golestan B, Vaseie M, Vaseie L, Khajeh-Kazemi R. Knowledge, attitude, and 371 practice of adults to the protective actions against sun in northwest Tehran, Iran. Arch Iran Med. $372 \quad 2011 ; 14(2): 126-31$.

373 36. Yan S, Xu F, Yang C, Li F, Fan J, Wang L, Cai M, Zhu J, Kan H, Xu J. Demographic 374 differences in sun protection beliefs and behavior: a community-based study in Shanghai, China. 375 Int J Environ Res Public Health. 2015;12(3):3232-45.

376 37. Day AK, Wilson CJ, Hutchinson AD, Roberts RM. The role of skin cancer knowledge in 377 sun-related behaviours: a systematic review. J Health Psychol. 2014;19(9):1143-62.

378 38. Fardouly J, Vartanian LR. Social Media and Body Image Concerns: Current Research and 379 Future Directions. Curr Opin Psychol. 2016;9:1-5.

380 39. Barlett CP, Vowels CL, Saucier DA. Meta-Analyses of the Effects of Media Images on 381 Men's Body-image Concerns. J Soc Clin Psychol. 2008;27(3):279-310.

382

40. Devos SA, Van der Endt JD, Broeckx W, Vandaele M, del Marmol V, Roseeuw D, Maselis 383 T. Sunscreen use and skin protection behaviour on the Belgian beach: a comparison 9 years later. Eur J Cancer Prev. 2012;21(5):474.

38541

42. lannacone MR, Hughes MCB, Green AC. Effects of sunscreen on skin cancer and photoaging. Photodermatol Photoimmunol Photomed. 2014;30(2-3):55-61.

43. Grossman DC, Curry SJ, Owens DK, Barry MJ, Caughey AB, Davidson KW, Doubeni CA, 389 Epling JW Jr, Kemper AR, Krist AH, Kubik M, Landefeld S, Mangione CM, Silverstein M, Simon 390 MA, Tseng CW. Behavioral Counseling to Prevent Skin Cancer: US Preventive Services Task 391 Force Recommendation Statement. JAMA. 2018;319(11):1134-42.

392 44. Skotarczak K, Osmola-Mańkowska A, Lodyga M, Polańska A, Mazur M, Adamski Z. 393 Photoprotection: facts and controversies. Eur Rev Med Pharmacol Sci. 2015;19(1):98-112.

394 45. Mancebo SE, Hu JY, Wang SQ. Sunscreens: a review of health benefits, regulations, and 395 controversies. Dermatol Clin. 2014;32(3):427-38, x. 
396 46. Olsen CM, Thompson BS, Green AC, Neale RE, Whiteman DC, QSkin Sun and Health 397 Study Group. Sun Protection and Skin Examination Practices in a Setting of High Ambient Solar 398 Radiation: A Population-Based Cohort Study. JAMA Dermatol. 2015;151(9):982-90.

399 47. Reuter NP, Bower M, Scoggins CR, Martin RCG, McMasters KM, Chagpar AB. The lower 400 incidence of melanoma in women may be related to increased preventative behaviors. Am J Surg. $401 \quad 2010 ; 200(6): 765-9$.

402 48. Kasparian NA, McLoone JK, Meiser B. Skin cancer-related prevention and screening 403 behaviors: a review of the literature. J Behav Med. 2009;32(5):406-28.

404 49. Blumthaler M. UV Monitoring for Public Health. Int J Environ Res Public Health. $4052018 ; 15(8)$.

406 50. Emmons KM, Geller AC, Puleo E, Savadatti SS, Hu SW, Gorham S, Werchniak AE; Dana407 Farber Skin Cancer Screening Group. Skin cancer education and early detection at the beach: a 408 randomized trial of dermatologist examination and biometric feedback. J Am Acad Dermatol. 409 2011;64(2):282-9.

410 51. Hay JL, Berwick M, Zielaskowski K, White KA, Rodríguez VM, Robers E, Guest DD, 411 Sussman A, Talamantes Y, Schwartz MR, Greb J, Bigney J, Kaphingst KA, Hunley K, Buller DB. 412 Implementing an Internet-Delivered Skin Cancer Genetic Testing Intervention to Improve Sun 413 Protection Behavior in a Diverse Population: Protocol for a Randomized Controlled Trial. JMIR 414 Res Protoc. 2017;6(4):e52.

415 52. Rodrigues AM, Sniehotta FF, Birch-Machin MA, Olivier P, Araújo-Soares V. Systematic 416 and Iterative Development of a Smartphone App to Promote Sun-Protection Among 417 Holidaymakers: Design of a Prototype and Results of Usability and Acceptability Testing. JMIR 418 Res Protoc. 2017;6(6):e112.

419 53. Rodrigues A, Sniehotta FF, Araujo-Soares V. Are Interventions to Promote Sun-Protective 420 Behaviors in Recreational and Tourist Settings Effective? A Systematic Review with Meta421 analysis and Moderator Analysis. Ann Behav Med. 2013;45(2):224-38. 
Figure 1

Map of the study area

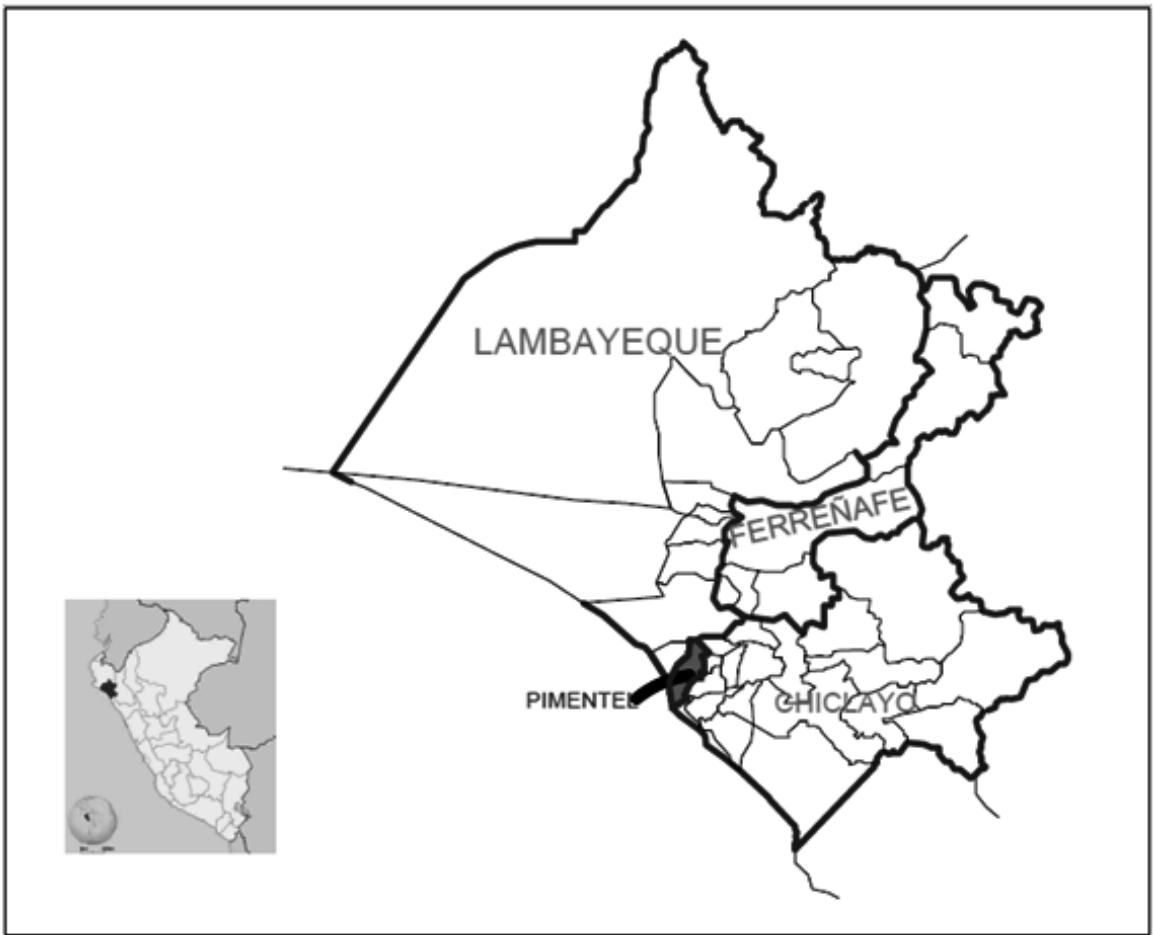




\section{Table 1 (on next page)}

Sociodemographic, skin color and phototype data $(n=410)$

* Median (Interquartile range) 
1 Table 1. Sociodemographic, skin color and phototype data $(n=410)$

\begin{tabular}{lc}
\hline Characteristics & $\mathbf{n ~ ( \% )}$ \\
\hline Sex & \\
Male & $176(42.9)$ \\
Female & $234(57.1)$ \\
Age (years) & $28(18-65)$ \\
Marital status & \\
Single & $226(55.1)$ \\
Married or living w/partner & $175(42.7)$ \\
Separated/Divorced & $6(1.5)$ \\
Widowed & $3(0.7)$ \\
Country of birth & \\
Peru & $401(98.1)$ \\
Argentina & $2(0.5)$ \\
Colombia & $3(0.7)$ \\
Ecuador & $2(0.5)$ \\
Mexico & $1(0.2)$ \\
Education & \\
None & $4(1.0)$ \\
Primary & $11(2.7)$ \\
Secondary & $137(33.4)$ \\
Higher Education & $258(62.9)$ \\
Skin color & \\
Very fair & $22(5.4)$ \\
Fair & $145(35.4)$ \\
Olive & $191(46.6)$ \\
Dark & $52(12.7)$ \\
Phototype & \\
I & $62(15.1)$ \\
II & $79(19.3)$ \\
III & $166(40.5)$ \\
IV & $103(25.1)$ \\
\hline &
\end{tabular}




\section{Table 2 (on next page)}

Sun-exposure habits and sunburns history

${ }^{*}$ Chi2 test 
1 Table 2: Sun-exposure habits and sunburns history

\begin{tabular}{|c|c|c|c|c|}
\hline Item & $\begin{array}{c}\text { Men } \\
\text { n (\%) }\end{array}$ & $\begin{array}{c}\text { Women } \\
\text { n (\%) }\end{array}$ & $\begin{array}{l}\text { Total } \\
\mathrm{n}(\%)\end{array}$ & $\mathbf{p}^{*}$ \\
\hline \multicolumn{5}{|c|}{$\begin{array}{l}\text { In relation with the last two summers, choose... } \\
\text { Days of sun on the beach }\end{array}$} \\
\hline None & $16(9.09)$ & $40(17.09)$ & $56(13.66)$ & \multirow[t]{5}{*}{0.028} \\
\hline $1-5$ & $95(53.98)$ & $120(51.28)$ & $215(52.44)$ & \\
\hline $6-15$ & $29(16.48)$ & $44(18.80)$ & $73(17.80)$ & \\
\hline $16-30$ & $17(9.66)$ & $9(3.85)$ & $26(6.34)$ & \\
\hline$>30$ & $19(10.80)$ & $21(8.97)$ & $40(9.76)$ & \\
\hline \multicolumn{5}{|c|}{ Hours of sun exposure on the beach } \\
\hline$<30$ minutes & $26(14.77)$ & $41(17.52)$ & $67(16.34)$ & \multirow[t]{4}{*}{0.706} \\
\hline 30 minutes -1 hour & $43(24.43)$ & $52(22.22)$ & $95(23.17)$ & \\
\hline $1-3$ hours & $65(36.93)$ & $93(79.74)$ & $158(38.54)$ & \\
\hline$>3$ hours & $42(23.86)$ & $48(20.51)$ & $90(21.95)$ & \\
\hline \multicolumn{5}{|l|}{ Hours of sun at midday } \\
\hline No sun & $24(13.64)$ & $42(17.95)$ & $66(16.10)$ & \multirow[t]{5}{*}{0.184} \\
\hline$<1$ hour & $48(27.27)$ & $42(17.95)$ & 90 (21.95) & \\
\hline $1-2$ hours & 38 (21.59) & $61(26.07)$ & $99(24.15)$ & \\
\hline $2-4$ hours & $39(22.16)$ & $56(23.93)$ & $95(23.17)$ & \\
\hline $4-6$ hours & $27(15.34)$ & $33(14.10)$ & $60(14.63)$ & \\
\hline \multicolumn{5}{|l|}{$\begin{array}{l}\text { Last summer... } \\
\text { Sunburns }\end{array}$} \\
\hline None & $63(35.80)$ & $92(39.32)$ & $155(37.80)$ & \multirow[t]{5}{*}{0.818} \\
\hline $1-2$ & 73 (41.48) & $100(42.74)$ & $173(42.20)$ & \\
\hline $3-5$ & $28(19.51)$ & 29 (12.39) & $57(13.90)$ & \\
\hline $6-10$ & $5(2.84)$ & $5(2.14)$ & $10(2.44)$ & \\
\hline$>10$ & $7(3.98)$ & $8(3.42)$ & $15(3.66)$ & \\
\hline
\end{tabular}

${ }^{*}$ Chi2 test 


\section{Table $\mathbf{3}$ (on next page)}

Participants' general knowledge about sun exposure

*Chi2 test 
1 Table 3. Participants' general knowledge about sun exposure

\begin{tabular}{|c|c|c|c|c|}
\hline Item & $\begin{array}{l}\text { Men } \\
\text { n (\%) }\end{array}$ & $\begin{array}{c}\text { Women } \\
\text { n (\%) }\end{array}$ & $\begin{array}{l}\text { Total } \\
\text { n (\%) }\end{array}$ & $\mathbf{p}^{*}$ \\
\hline \multicolumn{5}{|c|}{$\begin{array}{l}\text { Sun protection creams prevent aging of the } \\
\text { skin produced by solar radiation }\end{array}$} \\
\hline True & $107(60.80)$ & $139(59.40)$ & $246(60.0)$ & 0.776 \\
\hline False & $69(39.20)$ & $95(40.60)$ & $164(40.0)$ & \\
\hline Sun is the main cause of skin cancer & & & & 0.452 \\
\hline True & $163(92.61)$ & $221(94.44)$ & $384(93.66)$ & \\
\hline False & $13(7.39)$ & $13(5.56)$ & $26(6.34)$ & \\
\hline Sun produces marks on the skin & & & & 0.135 \\
\hline True & $152(86.36)$ & $213(91.03)$ & $365(89.02)$ & \\
\hline False & $24(13.64)$ & $21(8.97)$ & $45(10.98)$ & \\
\hline \multicolumn{5}{|l|}{$\begin{array}{l}\text { If I use sunscreen I can sunbathe without } \\
\text { any risk }\end{array}$} \\
\hline True & $79(44.89)$ & $92(39.32)$ & $171(41.71)$ & 0.258 \\
\hline False & $97(55.11)$ & $142(60.68)$ & $239(58.29)$ & \\
\hline \multicolumn{5}{|c|}{$\begin{array}{l}\text { Avoiding the midday sun (11-17 hours) is } \\
\text { the most efficient way of protecting my skin }\end{array}$} \\
\hline True & $137(77.84)$ & $176(75.21)$ & $313(76.34)$ & 0.536 \\
\hline False & $39(22.16)$ & $58(24.79)$ & $97(23.66)$ & \\
\hline \multicolumn{5}{|c|}{$\begin{array}{l}\text { Once my skin is tanned, I don't need to use } \\
\text { sun protection cream }\end{array}$} \\
\hline True & $42(23.86)$ & 27 (11.54) & 69 (16.83) & 0.001 \\
\hline False & $134(76.14)$ & 207 (88.46) & 341 (83.17) & \\
\hline
\end{tabular}

$2{ }^{*}$ Chi2 test 


\section{Table 4(on next page)}

Attitudes related with sun exposure

*Chi2 test 
1 Table 4. Attitudes related with sun exposure

\begin{tabular}{|c|c|c|c|c|}
\hline Item & $\begin{array}{l}\text { Men } \\
\mathrm{n}(\%)\end{array}$ & $\begin{array}{c}\text { Women } \\
\mathrm{n}(\%)\end{array}$ & $\begin{array}{l}\text { Total } \\
\mathrm{n}(\%)\end{array}$ & $\mathbf{p}^{*}$ \\
\hline \multicolumn{5}{|l|}{ When I am tanned my clothes look nicer } \\
\hline Totally agree / Agree & $61(34.66)$ & $60(25.64)$ & $121(29.51)$ & 0.048 \\
\hline Indifferent / Disagree / Totally disagree & $115(65.34)$ & $174(74.36)$ & $289(70.49)$ & \\
\hline \multicolumn{5}{|l|}{ Sunbathing helps prevent health problems } \\
\hline Totally agree / Agree & $76(43.18)$ & $109(46.58)$ & $185(45.12)$ & 0.494 \\
\hline Indifferent / Disagree / Totally disagree & $100(56.82)$ & $125(53.42)$ & $225(54.88)$ & \\
\hline \multicolumn{5}{|c|}{$\begin{array}{l}\text { I like the feeling of the sun on my skin when } \\
\text { I am lying on the beach }\end{array}$} \\
\hline Totally agree / Agree & $64(36.36)$ & $65(27.78)$ & $129(31.46)$ & 0.064 \\
\hline Indifferent / Disagree / Totally disagree & $112(63.64)$ & $169(72.22)$ & $281(54.88)$ & \\
\hline \multicolumn{5}{|l|}{$\begin{array}{l}\text { It is worth using sun protection cream to } \\
\text { avoid future problems }\end{array}$} \\
\hline Totally agree / Agree & $161(91.48)$ & $210(89.74)$ & $371(90.49)$ & 0.554 \\
\hline Indifferent / Disagree / Totally disagree & $15(8.52)$ & $24(10.26)$ & $39(9.51)$ & \\
\hline \multicolumn{5}{|l|}{ I find sun protection creams unpleasant } \\
\hline Totally agree / Agree & $52(29.55)$ & $69(29.49)$ & $121(29.51)$ & 0.990 \\
\hline Indifferent / Disagree / Totally disagree & $124(70.45)$ & $165(70.51)$ & $289(70.49)$ & \\
\hline \multicolumn{5}{|l|}{$\begin{array}{l}\text { It is worth using sun protection cream even } \\
\text { though I don't get a tan }\end{array}$} \\
\hline Totally agree / Agree & $136(77.27)$ & $183(78.21)$ & $319(77.80)$ & 0.822 \\
\hline Indifferent / Disagree / Totally disagree & $40(22.73)$ & $51(21.79)$ & $91(22.20)$ & \\
\hline \multicolumn{5}{|l|}{ People with a tan are more attractive } \\
\hline Totally agree / Agree & $67(38.07)$ & $79(33.76)$ & $146(35.61)$ & 0.367 \\
\hline Indifferent / Disagree / Totally disagree & $109(61.93)$ & $155(66.24)$ & $264(64.39)$ & \\
\hline \multicolumn{5}{|l|}{ Sunbathing is healthy for my body } \\
\hline Totally agree / Agree & $95(53.98)$ & $107(45.73)$ & $202(49.27)$ & 0.098 \\
\hline Indifferent / Disagree / Totally disagree & $81(46.02)$ & $127(54.27)$ & $208(50.73)$ & \\
\hline \multicolumn{5}{|l|}{ Sunbathing is relaxing } \\
\hline Totally agree / Agree & $112(63.64)$ & $108(46.15)$ & $220(53.66)$ & $<0.001$ \\
\hline Indifferent / Disagree / Totally disagree & $64(36.36)$ & $126(53.85)$ & $190(46.34)$ & \\
\hline \multicolumn{5}{|l|}{$\begin{array}{l}\text { Having a tan makes you look young and } \\
\text { relaxed }\end{array}$} \\
\hline Totally agree / Agree & $63(35.80)$ & $67(28.63)$ & $130(31.71)$ & 0.123 \\
\hline Indifferent / Disagree / Totally disagree & $113(64.20)$ & $167(71.37)$ & $280(68.29)$ & \\
\hline \multicolumn{5}{|l|}{ Sunbathing improves my mood } \\
\hline Totally agree / Agree & $108(61.36)$ & $115(49.15)$ & $223(54.39)$ & 0.014 \\
\hline Indifferent / Disagree / Totally disagree & $68(38.64)$ & $119(50.85)$ & $187(45.61)$ & \\
\hline \multicolumn{5}{|l|}{ I like sunbathing } \\
\hline Totally agree / Agree & $108(61.36)$ & $121(51.71)$ & $229(55.85)$ & 0.051 \\
\hline Indifferent / Disagree / Totally disagree & $68(38.64)$ & $113(48.29)$ & $181(44.15)$ & \\
\hline \multicolumn{5}{|l|}{$\begin{array}{l}\text { When I go to the beach I prefer to be in the } \\
\text { shade }\end{array}$} \\
\hline Totally agree / Agree & $128(72.73)$ & $173(73.93)$ & $301(73.41)$ & 0.785 \\
\hline Indifferent / Disagree / Totally disagree & $48(27.27)$ & $61(26.07)$ & $109(26.59)$ & \\
\hline
\end{tabular}

I don't like high-protection creams because they are anti-aesthetic 
Totally agree / Agree Indifferent / Disagree / Totally disagree ${ }^{*}$ Chi2 test
$53(30.11) \quad 62(26.50) \quad 115(28.05) \quad 0.420$

$123(69.89) \quad 172(73.50) \quad 295(71.95)$

2 


\section{Table 5(on next page)}

Sun protection practices

$\mathrm{SPF}=$ Sun Protection Factor $*$ Chi2 test 
1 Table 5. Sun protection practices

\begin{tabular}{|c|c|c|c|c|}
\hline Item & $\begin{array}{c}\text { Men } \\
\mathrm{n}(\%)\end{array}$ & $\begin{array}{c}\text { Women } \\
\text { n (\%) }\end{array}$ & $\begin{array}{l}\text { Total } \\
\mathrm{n}(\%)\end{array}$ & $\mathbf{p}^{*}$ \\
\hline \multicolumn{5}{|c|}{$\begin{array}{l}\text { When you go to the beach, you... } \\
\text { Use sunshade }\end{array}$} \\
\hline Always & $37(21.02)$ & $92(39.32)$ & $129(31.46)$ & \multirow[t]{5}{*}{0.001} \\
\hline Usually & $27(15.34)$ & $27(11.54)$ & $54(13.17)$ & \\
\hline Sometimes & $50(28.41)$ & 63 (26.92) & $113(27.56)$ & \\
\hline Almost never & $25(14.20)$ & $25(10.68)$ & $50(12.20)$ & \\
\hline Never & $37(21.02)$ & $27(11.54)$ & $64(15.61)$ & \\
\hline \multicolumn{5}{|l|}{ Use sunglasses } \\
\hline Always & $35(19.89)$ & $65(27.78)$ & $100(24.39)$ & \multirow[t]{5}{*}{0.406} \\
\hline Usually & $23(13.07)$ & $28(11.97)$ & $51(12.44)$ & \\
\hline Sometimes & $43(24.43)$ & 58 (24.79) & $101(24.63)$ & \\
\hline Almost never & $25(14.20)$ & $28(11.97)$ & 53 (12.93) & \\
\hline Never & $50(28.41)$ & $55(23.50)$ & $105(25.61)$ & \\
\hline \multicolumn{5}{|l|}{ Use hat or cap } \\
\hline Always & $57(32.39)$ & $73(31.20)$ & $130(31.71)$ & \multirow[t]{5}{*}{0.718} \\
\hline Usually & $28(15.91)$ & 35 (14.96) & $63(15.37)$ & \\
\hline Sometimes & $37(21.02)$ & $60(25.64)$ & $97(23.66)$ & \\
\hline Almost never & $20(11.36)$ & $30(12.82)$ & $50(12.20)$ & \\
\hline Never & $34(19.32)$ & 36 (15.38) & $70(17.07)$ & \\
\hline \multicolumn{5}{|c|}{ Wear long sleeves or long trousers } \\
\hline Always & $22(12.50)$ & $27(11.54)$ & $49(11.95)$ & \multirow[t]{5}{*}{0.742} \\
\hline Usually & $17(9.66)$ & $16(6.84)$ & $33(8.05)$ & \\
\hline Sometimes & $29(16.48)$ & $48(20.51)$ & $77(18.78)$ & \\
\hline Almost never & $33(18.75)$ & $45(19.23)$ & $78(19.02)$ & \\
\hline Never & $75(42.61)$ & $98(41.88)$ & $173(42.20)$ & \\
\hline \multicolumn{5}{|c|}{ Avoid sun $12.00-16.00$} \\
\hline Always & $38(21.59)$ & $60(25.64)$ & $98(23.90)$ & \multirow[t]{5}{*}{0.802} \\
\hline Usually & $32(18.18)$ & $44(18.80)$ & $76(18.54)$ & \\
\hline Sometimes & $61(34.66)$ & $72(30.77)$ & $133(32.44)$ & \\
\hline Almost never & $15(8.52)$ & $23(9.83)$ & $38(9.27)$ & \\
\hline Never & $30(17.05)$ & $35(14.96)$ & $65(15.85)$ & \\
\hline \multicolumn{5}{|c|}{ Use sunscreen (SPF $\geq 15$ ) } \\
\hline Always & $54(30.68)$ & $125(53.42)$ & $179(43.66)$ & \multirow[t]{5}{*}{$<0.001$} \\
\hline Usually & $37(21.02)$ & $46(19.66)$ & $83(20.24)$ & \\
\hline Sometimes & $42(23.86)$ & $43(18.38)$ & $85(20.73)$ & \\
\hline Almost never & $14(7.95)$ & $10(4.27)$ & $24(5.85)$ & \\
\hline Never & $29(16.48)$ & $10(4.27)$ & 39 (9.51) & \\
\hline
\end{tabular}

SPF $=$ Sun Protection Factor

${ }^{*}$ Chi2 test 